\title{
A large lung gene expression study identifying fibulin-5 as a novel player in tissue repair in COPD
}

\author{
Corry-Anke Brandsma, ${ }^{1,2}$ Maarten van den Berge, ${ }^{2,3}$ Dirkje S Postma, ${ }^{2,3}$ \\ Marnix R Jonker, ${ }^{1,2}$ Sharon Brouwer, ${ }^{1,2}$ Peter D Paré, ${ }^{4,5}$ Don D Sin, ${ }^{4,5}$ \\ Yohan Bossé, ${ }^{6,7}$ Michel Laviolette, ${ }^{6}$ Juha Karjalainen, ${ }^{8}$ Rudolf S N Fehrmann, ${ }^{8}$ \\ David C Nickle, ${ }^{9}$ Ke Hao, $^{9}$ Anita I R Spanjer, ${ }^{2,10}$ Wim Timens, ${ }^{1,2}$ Lude Franke $^{8}$
}

- Additional material is published online only. To view please visit the journal online (http://dx.doi.org/10.1136/ thoraxjnl-2014-205091)

For numbered affiliations see end of article.

\section{Correspondence to} Dr Corry-Anke Brandsma, Department of Pathology and Medical Biology, University Medical Center Groningen, PO Box 30.001, Groningen 9700 RB, The Netherlands; c.a.brandsma@umcg.nl

Received 6 January 2014 Revised 15 May 2014 Accepted 12 June 2014 Published Online First 2 July 2014

\section{SLinked}

- http://dx.doi.org/10.1136/ thoraxjnl-2014-205887

\section{CrossMark}

To cite: Brandsma $C-A$, van den Berge $\mathrm{M}$, Postma DS, et al. Thorax 2015;70: 21-32.

\section{ABSTRACT}

Background Chronic obstructive pulmonary disease (COPD) is a progressive, incurable lung disease characterised by abnormal tissue repair causing emphysema and small airways fibrosis. Since current therapy cannot modify this abnormal repair, it is crucial to unravel its underlying molecular mechanisms. Unbiased analysis of genome-wide gene expression profiles in lung tissue provides a powerful tool to investigate this.

Methods We performed genome-wide gene expression profiling in 581 lung tissue samples from current and ex-smokers with $(n=311)$ and without COPD $(n=270)$. Subsequently, quantitative $P C R$, western blot and immunohistochemical analyses were performed to validate our main findings.

Results 112 genes were found to be upregulated in patients with COPD compared with controls, whereas 61 genes were downregulated. Among the most upregulated genes were fibulin-5 (FBLN5), elastin (ELN), latent transforming growth factor $\beta$ binding protein 2 (LTBP2) and microfibrillar associated protein 4 (MFAP4), all implicated in elastogenesis. Our gene expression findings were validated at mRNA and protein level. We demonstrated higher ELN gene expression in COPD lung tissue and similar trends for FBLN5 and MFAP4, and negative correlations with lung function. FBLN5 protein levels were increased in COPD lung tissue and cleaved, possibly non-functional FBLN5 protein was present. Strong coexpression of FBLN5, ELN, LTBP2 and MFAP4 in lung tissue and in silico analysis indicated cofunctionality of these genes. Finally, colocalisation of FBLN5, MFAP4 and LTBP2 with elastic fibres was demonstrated in lung tissue.

Conclusions We identified a clear gene signature for elastogenesis in COPD and propose FBLN5 as a novel player in tissue repair in COPD.

\section{INTRODUCTION}

Chronic obstructive pulmonary disease (COPD) is a chronic and progressive lung disease with a large impact on patients and society and is mainly caused by cigarette smoking. There is no cure available for COPD and current drugs are mainly effective in improving symptoms and exacerbations but generally do not slow down the progression of the disease. Quitting smoking can reduce the accelerated lung function decline in some but not all

\section{Key messages}

What is the key question?

- Which relevant lung tissue gene expression changes can explain the mechanisms behind abnormal tissue repair in chronic obstructive pulmonary disease (COPD)?

\section{What is the bottom line?}

- Using genome-wide gene expression profiling in a large number of lung tissue samples from patients with COPD and non-COPD controls, we identified a clear COPD gene signature with increased expression of genes related to elastogenesis, with fibulin-5 as a main player.

\section{Why read on?}

- Our findings provide much needed insights in lung tissue gene expression changes in COPD and point out fibulin-5 as a potential novel player in tissue repair in COPD.

patients with COPD and it does not restore lost lung function.

Pathologically, COPD is characterised by distinct features, including emphysema with the destruction of alveolar lung tissue and fibrosis of the (small) airways with airway wall thickening. ${ }^{1}$ Although emphysema and airway wall thickening occur in close proximity to each other, they seem to be driven by different processes since emphysematous destruction is characterised by insufficient extracellular matrix (ECM) production, indicating a defective repair process, whereas airway wall thickening is the result of an exaggerated repair process accompanied by a marked increase in ECM. Both processes are important contributors to loss of lung function in patients with COPD. Hogg and colleagues recently demonstrated that small airway wall thickening and loss of small airways precedes emphysematous lung tissue destruction in patients with COPD, suggesting a relation between these processes. ${ }^{2}$

The exact nature of the abnormal repair processes in COPD lungs is unknown, hence there is no effective treatment to prevent further lung tissue damage or induce repair. A better understanding of regulation of the repair processes and the underlying molecular mechanisms is thus crucial. 
Unbiased analysis of genome-wide gene expression in lung tissue provides a powerful tool to investigate these molecular mechanisms. However, studies using this approach have been hindered thus far by small sample sizes due to the limited availability of lung tissue samples. ${ }^{3-7}$ As part of a Lung eQTL Consortium, ${ }^{8-10}$ we have performed an unbiased analysis of genome-wide gene-expression profiles in lung tissue specimens derived from a large number $(\mathrm{N}=581)$ of well characterised current and ex-smokers with $(\mathrm{N}=311)$ and without $(\mathrm{N}=270)$ COPD.

\section{METHODS}

Detailed methods can be found in the online supplement.

\section{Patients}

Gene expression data were used from 311 patients with COPD and 270 non-COPD controls who were part of the Lung eQTL dataset from three academic sites. ${ }^{8} 9$ Lung tissue samples were collected from patients undergoing lung surgery for various reasons, mostly therapeutic resection of lung tumours, but also lung transplantation. In case of tumour resections, macroscopically normal lung tissue was taken far distant from the tumour and histology of all samples was checked for abnormalities using standard haematoxylin and eosin staining. Lung samples were obtained in accordance with local ethical guidelines (for a detailed description, see Hao et $a l^{8}$ ). In the current analyses, we included current and ex-smokers $>40$ years with $\geq 5$ pack-years. COPD was defined as an $\mathrm{FEV}_{1} /$ FVC ratio $<70 \%$. Non-COPD control was defined as an $\mathrm{FEV}_{1} /$ $\mathrm{FVC} \geq 70 \%$ predicted. In case lung tissue samples were derived from healthy donors, no data on $\mathrm{FEV}_{1}$ or $\mathrm{FEV}_{1} / \mathrm{FVC}$ ratio were available. For $\mathrm{FEV}_{1}$ and $\mathrm{FEV}_{1} / \mathrm{FVC}$, pre-bronchodilator values were used when post-bronchodilator values were not available. Subjects with other lung diseases such as asthma, cystic fibrosis or interstitial lung diseases were excluded.

\section{Gene expression assays}

mRNA profiling was performed by Rosetta Inpharmatics Gene Expression Laboratory (Seattle, Washington, USA) using custom Affymetrix HU133 arrays (GEO platform GPL10379), consisting of 751 control and 51627 non-control probe sets as described previously. ${ }^{8}$ Gene expression normalisation was performed using Robust Multi-array Average and every probe set was normalised; that is, the mean expression was set to zero and the SD to one. We corrected for strong expression differences between the lung tissue samples due to unknown factors (eg, batch or technical effects) by correcting for the first 25 principal components, as described previously. ${ }^{11}$

We analysed the three cohorts separately, and corrected for potential confounders: age, gender, pack-years and smoking status (current vs former). We performed t tests to find differentially expressed genes between patients with COPD and controls. We then used an inverse variance meta-analysis to identify genes that were differentially expressed and behaved in the same direction across all three cohorts. We used the false discovery rate (FDR) to control for multiple testing. We report on a set of differentially expressed genes of which we accepted that $20 \%$ might be false positives. We observed that a nominal $\mathrm{p}<0.001$ resulted in 252 differentially expressed genes in the real analysis, whereas we would expect 51.6 by chance, corresponding to an FDR of 0.20 .

\section{GeneNetwork analysis}

A new method was used to gain insight into the potential gene function of differentially expressed genes, that is, GeneNetwork. This method uses an independent gene expression dataset of
77840 samples to predict the function of genes in an unbiased way, as recently employed. ${ }^{12}$ We used this method to predict (currently unknown) gene functions based on known biological pathways available in the molecular signatures database MSigDB (http://www.broadinstitute.org) and additionally used this information for pathway enrichment analyses and cofunctionality networks. Knockout information from the Mouse Genome Informatics database was collected for genes for which human orthologues exist to predict phenotypes in mice for which currently no knockout has been described.

\section{Quantitative PCR validation}

Quantitative PCR (qPCR) was used to confirm the expression levels of ELN (elastin), FBLN5 (fibulin-5), MFAP4 (microfibrillar associated protein) and LTBP2 (latent transforming growth factor (TGF)- $\beta$ binding protein 2 ) in lung tissue samples from the Groningen cohort.

Additionally, FBLN5 expression was analysed in primary pulmonary fibroblasts treated with or without TGF $\beta$ and cigarette smoke extract (CSE) from patients with stage IV COPD and non-COPD controls.

\section{Histology}

Immunohistochemical staining for FBLN5, MFAP4 and LTBP2 was performed on paraffin embedded lung tissue samples from the Groningen cohort to localise protein expression in lung tissue and assess the presence of these proteins in elastic fibres.

\section{Western blot analysis}

Western blot analyses was performed to measure total protein levels of FBLN5, ELN and MFAP4 in lung tissue and to identify the presence of the cleaved form of FBLN5.

\section{Statistics}

Gene expression analyses were performed using the eQTLMappingPipeline as previously described. ${ }^{13}$ Additional statistical analyses were performed using IBM SPSS Statistics 22 and R statistical software V.2.12.0. Differences in clinical characteristics were analysed using Mann-Whitney U (MWU) tests. For qPCR validation, MWU tests were used and increased gene expression and a one-sided $\mathrm{p}$ value $<0.05$ was considered a positive validation. Differences in FBLN5 expression levels in COPD and control fibroblasts and differences in FBLN5 protein levels in lung tissue were assessed using MWU tests and a two-sided p value $<0.05$ was considered significant. The relation between $\mathrm{FEV}_{1}$ and FBLN5, ELN, LTBP2 and MFAP4 expression and the relation between mRNA expression of these four genes in lung tissue was assessed by Spearman's correlation. A p $<0.05$ was considered significant.

\section{RESULTS}

\section{Subject characteristics}

Table 1 presents the clinical characteristics of the subjects. We included 146 subjects from the Groningen cohort, 282 from the Laval cohort and 153 from the UBC cohort. The subjects from the Groningen cohort were somewhat younger than those from Laval and UBC, had less pack-years smoked and had more severe COPD. Overall, patients with COPD and non-COPD controls did not differ in age, gender and smoking status, but patients with COPD had more pack-years smoked than the non-COPD controls. Since these phenotypic differences exist between the cohorts we performed subsequent analyses per cohort separately, followed by a meta-analysis. 
Table 1 Subject characteristics

\begin{tabular}{|c|c|c|c|c|c|c|c|c|}
\hline & \multicolumn{2}{|l|}{ Groningen } & \multicolumn{2}{|l|}{ Laval } & \multicolumn{2}{|l|}{ UBC } & \multicolumn{2}{|l|}{ All centres } \\
\hline & COPD & No COPD & COPD & No COPD & COPD & No COPD & COPD & No COPD \\
\hline Number & 101 & 45 & 147 & 135 & 63 & 90 & 311 & 270 \\
\hline Age, years & $58.0(52.0-65.0)$ & $60.0(54.0-66.0)$ & $66.0(59.0-71.0)^{*}$ & $62.0(53.5-68.0)$ & $65.0(58.0-71.0)^{*}$ & $62.0(56.0-70.75)$ & $64.0(56.0-71.0)$ & $61.5(54.0-68.8) \dagger$ \\
\hline Male/female, N & $56 / 45$ & $20 / 25$ & $83 / 64$ & $76 / 59$ & $43 / 20$ & $49 / 41$ & $182 / 129$ & $145 / 125$ \\
\hline \multicolumn{9}{|l|}{ Smoking } \\
\hline$\%$ Current $/ \%$ ex & $19 / 81$ & $44 / 56$ & $26 / 74$ & $16 / 84 \ddagger$ & $51 / 49^{*}$ & $34 / 66$ & $29 / 71$ & $27 / 73$ \\
\hline Pack-years, N & $33.0(22.1-44.5)$ & $35.0(21.0-41.0)$ & $50.0(40.0-60.0)^{*}$ & $38.4(25.0-46.0)$ & $47.5(34.9-74.0)^{*}$ & $37.8(25.0-48.9)$ & $42.0(30.0-58.0)$ & $37.5(25.0-48.0) \dagger$ \\
\hline \multicolumn{9}{|l|}{ GOLD stage, $N$} \\
\hline 1 & 0 & & 0 & & 1 & & 1 & \\
\hline II & 30 & & 134 & & 52 & & 216 & \\
\hline III & 11 & & 12 & & 4 & & 27 & \\
\hline IV & 49 & & 1 & & 6 & & 56 & \\
\hline Not classified & 11 & & 0 & & 0 & & 11 & \\
\hline $\mathrm{FEV}_{1}, \%$ predicted & $26.5(18.4-57.8)$ & $96.0(89.2-104.8)$ & $67.4(59.1-73.7)^{*}$ & $94.3(87.7-102.9)$ & $67.4(58.2-74.3)^{*}$ & $99.5(89.5-108.7)$ & $64.3(46.6-72.4)$ & $95.5(88.8-106.2) \dagger$ \\
\hline $\mathrm{FEV}_{1} / \mathrm{FVC}, \%$ & $42.6(27.6-57.4)$ & $75.8(72.9-80.0)$ & $59.2(52.8-64.7)^{*}$ & $75.3(73.2-78.2)$ & $58.1(51.3-63.4)^{*}$ & $76.6(73.3-79.5)$ & $56.3(45.9-63.5)$ & $75.6(73.2-79.1) \dagger$ \\
\hline TLCO, \%predicted & - & - & $79.0(63.5-91.0)$ & $92.0(76.3-108.0)$ & $67.8(51.0-76.6)$ & $85.2(75.1-94.4)$ & 73.0 (59.7-87.8) & $89.0(76.0-101.7) \dagger$ \\
\hline
\end{tabular}

\section{Differentially expressed genes in COPD}

The expression of 171 probe sets corresponding to 112 known genes was upregulated in patients with COPD versus non-COPD controls, and the expression of 81 probe sets corresponding to 61 known genes was downregulated at a $\mathrm{p}$ value $<0.001$, corresponding to an FDR of $20 \%$. A heatmap of these findings is shown in figure 1. The complete list of all probe sets and statistics is shown in online supplementary table S1. Among the most upregulated genes were FBLN5, microtubule-actin cross linking factor 1 (MACF1) and ELN. Among the most downregulated genes were immunoglobulin heavy chain constant region $\mu$ (IGHM), vascular endothelial growth factor $\alpha$ (VEGFA) and periostin (POSTN).
Figure 1 Heatmap of differentially expressed genes in chronic obstructive pulmonary disease (COPD). The heatmap shows differential gene expression $(p<0.001)$ between COPD and non-COPD control lung tissue for the three patients cohorts from Groningen, Quebec and Vancouver. Each probe set is shown separately and for several genes we found more than one significant probe set. The coloured, grey and white bars above the heatmap indicate the different groups of lung tissue samples. Genes with a higher expression in COPD lung tissue are shown in the upper part of the heatmap, genes with a lower expression in the lower part. Blue represents lower and red higher relative gene expression. The genes most relevant for this manuscript are highlighted in red on the left side of the heatmap.

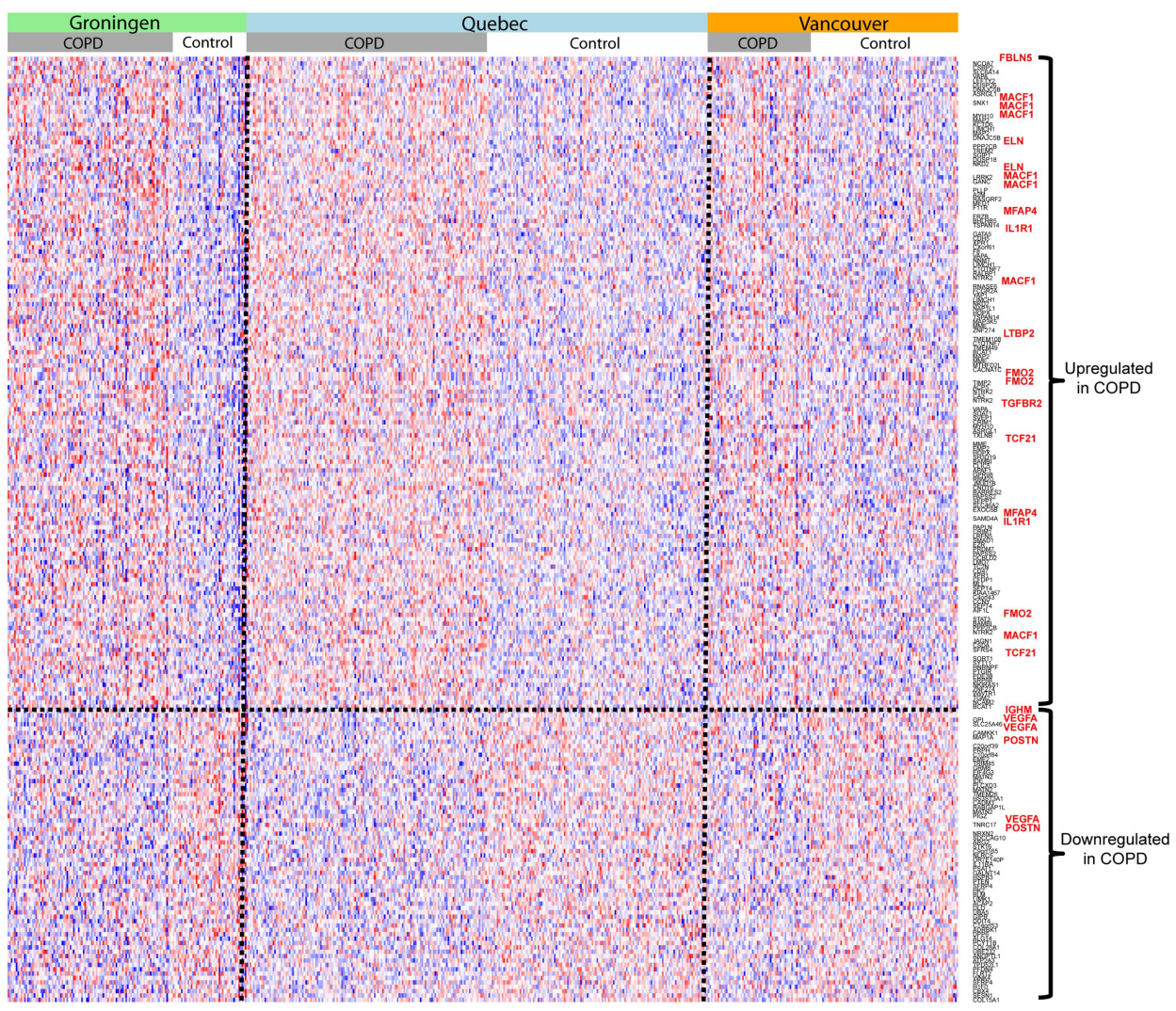


Table 2 Pathway enrichment based on gene function prediction of genes upregulated in COPD

\begin{tabular}{|c|c|c|c|}
\hline \multicolumn{2}{|l|}{ Biological processes } & \multicolumn{2}{|l|}{ Mouse genome informatics } \\
\hline Term & p Value & Term & $\mathrm{p}$ Value \\
\hline Response to oxygen levels & $8.60 \mathrm{E}-13$ & Abnormal pulmonary alveolus morphology & $5.78 \mathrm{E}-12$ \\
\hline Regulation of cell migration & $3.72 \mathrm{E}-12$ & Abnormal lung vasculature morphology & 2.03E-11 \\
\hline Regulation of locomotion & 4.39E-12 & Weight loss & $4.73 \mathrm{E}-11$ \\
\hline Regulation of anatomical structure morphogenesis & $6.08 \mathrm{E}-12$ & Thick pulmonary interalveolar septum & $7.60 \mathrm{E}-11$ \\
\hline Regulation of cell motility & $1.58 \mathrm{E}-11$ & Pericardial effusion & $8.16 \mathrm{E}-11$ \\
\hline Regulation of cellular component movement & $1.66 \mathrm{E}-11$ & Abnormal vascular wound healing & $1.05 \mathrm{E}-10$ \\
\hline Regulation of endocytosis & $2.12 \mathrm{E}-11$ & Abnormal lung development & $1.14 \mathrm{E}-10$ \\
\hline Regulation of growth & $3.53 \mathrm{E}-11$ & Abnormal myocardium layer morphology & $1.88 \mathrm{E}-10$ \\
\hline Respiratory tube development & 4.13E-11 & Lethargy & $2.68 \mathrm{E}-10$ \\
\hline Regulation of cell adhesion & $5.54 \mathrm{E}-11$ & Abnormal vascular smooth muscle physiology & $3.69 \mathrm{E}-10$ \\
\hline Circulatory system process & $6.92 \mathrm{E}-11$ & Atelectasis & $1.26 \mathrm{E}-09$ \\
\hline Vasculature development & $1.00 \mathrm{E}-10$ & Abnormal cardiovascular system physiology & $1.61 \mathrm{E}-09$ \\
\hline Lung development & $1.08 \mathrm{E}-10$ & Abnormal heart ventricle morphology & $1.80 \mathrm{E}-09$ \\
\hline Blood vessel morphogenesis & $1.47 \mathrm{E}-10$ & Abnormal angiogenesis & $3.11 \mathrm{E}-09$ \\
\hline Response to hypoxia & $1.78 \mathrm{E}-10$ & Abnormal fear/anxiety-related behaviour & $3.59 \mathrm{E}-09$ \\
\hline Blood circulation & $1.89 \mathrm{E}-10$ & Abnormal response/metabolism to endogenous compounds & $3.76 \mathrm{E}-09$ \\
\hline Regulation of system process & $2.37 \mathrm{E}-10$ & Increased glomerular capsule space & $9.22 \mathrm{E}-09$ \\
\hline Blood vessel development & $2.72 \mathrm{E}-10$ & Absent heartbeat & $1.12 \mathrm{E}-08$ \\
\hline Response to mechanical stimulus & $3.27 \mathrm{E}-10$ & Decreased response of heart to induced stress & $1.29 \mathrm{E}-08$ \\
\hline Regulation of vesicle-mediated transport & $3.70 \mathrm{E}-10$ & Abnormal production of surfactant & $1.31 \mathrm{E}-08$ \\
\hline Angiogenesis & $5.56 \mathrm{E}-10$ & Dilated heart right ventricle & $1.50 \mathrm{E}-08$ \\
\hline Response to hyperoxia & $6.36 \mathrm{E}-10$ & Hydronephrosis & $1.64 \mathrm{E}-08$ \\
\hline Regulation of angiogenesis & $9.52 \mathrm{E}-10$ & Abnormal cardiac muscle contractility & $1.81 \mathrm{E}-08$ \\
\hline Vascular process in circulatory system & $9.53 \mathrm{E}-10$ & Abnormal cell migration & $2.00 \mathrm{E}-08$ \\
\hline Fibroblast migration & $1.10 \mathrm{E}-09$ & Abnormal macrophage morphology & $2.00 \mathrm{E}-08$ \\
\hline Negative regulation of cell migration & $1.29 \mathrm{E}-09$ & Decreased cardiac muscle contractility & $2.18 \mathrm{E}-08$ \\
\hline Positive regulation of angiogenesis & 1.69E-09 & Abnormal stria vascularis morphology & $2.41 \mathrm{E}-08$ \\
\hline Regulation of developmental growth & 1.89E-09 & Ostium primum atrial septal defect & $2.87 \mathrm{E}-08$ \\
\hline Tube development & $1.94 \mathrm{E}-09$ & Abnormal kidney morphology & $3.55 \mathrm{E}-08$ \\
\hline Negative regulation of cell motility & $2.22 \mathrm{E}-09$ & Decreased heart rate & $3.90 \mathrm{E}-08$ \\
\hline Respiratory system development & $2.41 \mathrm{E}-09$ & Enlarged heart atrium & $4.03 \mathrm{E}-08$ \\
\hline Negative regulation of cellular component movement & 2.87E-09 & Abnormal vascular smooth muscle morphology & $4.58 \mathrm{E}-08$ \\
\hline Cell-cell adhesion & $2.88 \mathrm{E}-09$ & Decreased skin tensile strength & $4.69 \mathrm{E}-08$ \\
\hline Negative regulation of epithelial cell proliferation & $3.25 \mathrm{E}-09$ & Abnormal vitelline vascular remodelling & $5.68 \mathrm{E}-08$ \\
\hline Regulation of chemotaxis & $3.60 \mathrm{E}-09$ & Abnormal eating/drinking behaviour & $6.47 \mathrm{E}-08$ \\
\hline Developmental growth & $5.69 \mathrm{E}-09$ & Abnormal myocardial fibre physiology & $6.72 \mathrm{E}-08$ \\
\hline Regulation of blood vessel size & $6.31 \mathrm{E}-09$ & Abnormal heart development & $6.82 \mathrm{E}-08$ \\
\hline Negative regulation of locomotion & $6.80 \mathrm{E}-09$ & Dilated heart left ventricle & $7.58 \mathrm{E}-08$ \\
\hline Actin filament-based process & 7.89E-09 & Abnormal CNS glial cell morphology & $9.51 \mathrm{E}-08$ \\
\hline Positive regulation of endocytosis & 8.18E-09 & Increased cranium width & $1.14 \mathrm{E}-07$ \\
\hline Glomerulus development & $8.30 \mathrm{E}-09$ & Increased response of heart to induced stress & $1.24 \mathrm{E}-07$ \\
\hline Regulation of tube size & $8.31 \mathrm{E}-09$ & Increased circulating creatinine level & $1.31 \mathrm{E}-07$ \\
\hline Regulation of behaviour & $1.03 \mathrm{E}-08$ & Increased systemic arterial blood pressure & 1.37E-07 \\
\hline Positive regulation of cell adhesion & $1.27 \mathrm{E}-08$ & Abnormal lung morphology & $1.57 \mathrm{E}-07$ \\
\hline Regulation of endothelial cell migration & $1.43 \mathrm{E}-08$ & Abnormal heart shape & $1.64 \mathrm{E}-07$ \\
\hline Response to steroid hormone stimulus & $1.79 \mathrm{E}-08$ & Cyanosis & $2.00 \mathrm{E}-07$ \\
\hline Regulation of muscle system process & $1.91 \mathrm{E}-08$ & Increased angiogenesis & $2.74 \mathrm{E}-07$ \\
\hline Positive regulation of cell migration & $2.35 \mathrm{E}-08$ & Haemorrhage & $2.81 \mathrm{E}-07$ \\
\hline Striated muscle tissue development & $2.59 \mathrm{E}-08$ & Decreased brain weight & $2.92 \mathrm{E}-07$ \\
\hline \multirow[t]{9}{*}{ Actin cytoskeleton organisation } & $2.60 \mathrm{E}-08$ & Cardiac hypertrophy & $3.10 \mathrm{E}-07$ \\
\hline & & Hypoactivity & $3.60 \mathrm{E}-07$ \\
\hline & & Abnormal osteoclast morphology & $3.69 \mathrm{E}-07$ \\
\hline & & Abnormal epididymal fat pad morphology & $3.80 \mathrm{E}-07$ \\
\hline & & Increased type II pneumocyte number & $4.25 \mathrm{E}-07$ \\
\hline & & Abnormal heart valve morphology & $4.39 \mathrm{E}-07$ \\
\hline & & Pulmonary hypoplasia & $4.85 \mathrm{E}-07$ \\
\hline & & Edema & $5.19 \mathrm{E}-07$ \\
\hline & & Altered response to myocardial infarction & $5.24 \mathrm{E}-07$ \\
\hline
\end{tabular}


Table 2 Continued

\begin{tabular}{|c|c|c|c|}
\hline \multicolumn{2}{|c|}{ Biological processes } & \multicolumn{2}{|l|}{ Mouse genome informatics } \\
\hline Term & p Value & Term & p Value \\
\hline & & Stria vascularis degeneration & 5.57E-07 \\
\hline & & Decreased bone volume & $5.59 \mathrm{E}-07$ \\
\hline & & Disorganised myocardium & $6.00 \mathrm{E}-07$ \\
\hline & & Abnormal visceral yolk sac morphology & $6.16 \mathrm{E}-07$ \\
\hline & & Abnormal ureter morphology & 7.39E-07 \\
\hline & & Increased urine protein level & 7.77E-07 \\
\hline & & Enlarged heart & 8.47E-07 \\
\hline & & Decreased angiogenesis & 8.67E-07 \\
\hline & & Decreased survivor rate & $9.18 \mathrm{E}-07$ \\
\hline & & Partial prenatal lethality & $9.89 \mathrm{E}-07$ \\
\hline & & Abnormal renal glomerulus morphology & $1.06 \mathrm{E}-06$ \\
\hline & & Decreased brainstem auditory evoked potential & $1.06 \mathrm{E}-06$ \\
\hline & & Abnormal astrocyte morphology & 1.09E-06 \\
\hline & & Complete lethality throughout fetal growth and development & $1.28 \mathrm{E}-06$ \\
\hline & & Thin myocardium & $1.39 \mathrm{E}-06$ \\
\hline & & Failure of initiation of embryo turning & $1.40 \mathrm{E}-06$ \\
\hline & & Increased insulin sensitivity & $1.55 \mathrm{E}-06$ \\
\hline & & Abnormal type II pneumocyte morphology & $1.76 \mathrm{E}-06$ \\
\hline & & Congestive heart failure & $1.81 \mathrm{E}-06$ \\
\hline & & Expanded mesangial matrix & $1.89 \mathrm{E}-06$ \\
\hline & & Emphysema & $2.01 \mathrm{E}-06$ \\
\hline
\end{tabular}

From the upregulated genes, FBLN5 is most interesting in the context of COPD pathogenesis. This gene has been shown to be essential for elastic fibre formation, it is abundantly expressed during lung development, ${ }^{14}$ and FBLN5 knockout mice were shown to develop severe emphysema. ${ }^{15} 16$ Moreover, three additional genes implicated in elastogenesis were found to be among the most upregulated genes in COPD, that is, ELN, LTBP2 and MFAP4. ${ }^{17} 18$

Other upregulated genes considered to be of potential interest for COPD pathogenesis are TGF $\beta$ receptor-2 (TGFBR2), $\alpha$-2-macroglobulin $(A 2 M)$, interleukin 1 receptor type 1 (IL1R1), transcription factor 21 (TCF21) and metallopeptidase inhibitor 2 (TIMP2).

Given the potential novel roles for FBLN5, LTBP2 and MFAP4 in elastogenesis in COPD, we decided to further focus on these genes in this article.

\section{Pathways and phenotypes related to (abnormal) lung development and emphysema are enriched among genes upregulated in COPD}

We subsequently assessed the enrichment of biological processes and predicted phenotypes among the 112 genes upregulated in patients with COPD at $p<0.001$. While such an analysis is typically conducted using gene set enrichment analysis (GSEA), we performed a similar analysis but instead of using only established gene functions in GSEA, we used the predicted gene functions that were based on the independent gene expression dataset of 77840 samples.

Enrichment was found for biological processes involved in lung development, cell adhesion and fibroblast migration, and several phenotypes related to abnormal lung development and lung morphology and emphysema (table 2).

\section{Overlapping gene function and cofunctionality for elastogenesis genes}

To gain more insight in the function of the four genes related to elastogenesis, we used our GeneNetwork method to predict potential functions of genes (see online supplementary methods). We found a striking overlap in predicted gene function for the four elastogenesis genes, most being predicted to be involved in ECM organisation, collagen fibril organisation, cellmatrix adhesion, and the TGF $\beta$ receptor signalling pathway (table 3A). Interestingly, we also found that all four genes related to elastogenesis were predicted to give an emphysematous phenotype in knockout mice (table 3B). Other predicted phenotypes in knockout mice were overexpanded pulmonary alveoli, impaired lung alveolar development and dilated airways.

When assessing which genes share many predicted functions, we found a very consistent gene network for the genes upregulated in COPD at $\mathrm{p}<0.001$. The four genes related to elastogenesis (FBLN5, ELN, MFAP4 and LTBP2) clearly cluster together and are surrounded by other genes relevant for COPD pathogenesis (figure 2). The gene network for the downregulated genes was less consistent (see online supplemental figure S1).

\section{Validation of gene expression findings using $\mathrm{qPCR}$}

qPCR for FBLN5, ELN, MFAP4 and LTBP2 was performed on lung tissue samples from 45 patients with COPD and 42 non-COPD controls from the Groningen cohort. Subject characteristics are given in online supplementary table S2.

We found significantly higher ELN expression in COPD compared with control lung tissue and similar trends for FBLN5 $(\mathrm{p}=0.08)$ and MFAP4 $(\mathrm{p}=0.08)$ (figure $3 \mathrm{~A})$. There was no difference in $L T B P 2$ expression. In addition, significant negative correlations were found between $\mathrm{FEV}_{1}$ and FBLN5 (figure 3B), and $\mathrm{FEV}_{1}$ and $E L N$, and $\mathrm{FEV}_{1}$ and MFAP4 (see online supplemental 
Table 3A Gene function prediction in biological pathways

\begin{tabular}{|c|c|c|c|c|c|c|c|}
\hline \multicolumn{2}{|l|}{$E L N$} & \multicolumn{2}{|l|}{ FBLN5 } & \multicolumn{2}{|l|}{ MFAP4 } & \multicolumn{2}{|l|}{ LTBP2 } \\
\hline Biological pathways & p Value & Biological pathways & p Value & Biological pathways & p Value & Biological pathways & $\mathrm{p}$ Value \\
\hline Collagen fibril organisation & $8.46 \mathrm{E}-25$ & $\begin{array}{l}\text { Extracellular structure } \\
\text { organisation }\end{array}$ & 4.66E-12 & $\begin{array}{l}\text { Extracellular structure } \\
\text { organisation }\end{array}$ & $1.43 \mathrm{E}-21$ & $\begin{array}{l}\text { Regulation of leukocyte } \\
\text { chemotaxis }\end{array}$ & $8.61 \mathrm{E}-22$ \\
\hline $\begin{array}{l}\text { Extracellular structure } \\
\text { organisation }\end{array}$ & $2.35 \mathrm{E}-18$ & Extracellular matrix organisation & $4.66 \mathrm{E}-12$ & $\begin{array}{l}\text { Extracellular matrix } \\
\text { organisation }\end{array}$ & $1.43 \mathrm{E}-21$ & Cell-substrate adhesion & $2.18 \mathrm{E}-21$ \\
\hline $\begin{array}{l}\text { Extracellular matrix } \\
\text { organisation }\end{array}$ & $2.35 \mathrm{E}-18$ & $\begin{array}{l}\text { Regulation of systemic arterial blood } \\
\text { pressure by hormone }\end{array}$ & $5.22 \mathrm{E}-11$ & $\begin{array}{l}\text { Negative regulation of } \\
\text { androgen receptor } \\
\text { signalling pathway }\end{array}$ & $4.33 \mathrm{E}-13$ & Cell-matrix adhesion & $1.20 \mathrm{E}-17$ \\
\hline Blood vessel remodelling & $6.07 \mathrm{E}-17$ & Response to amino acid stimulus & $2.38 \mathrm{E}-10$ & $\begin{array}{l}\text { TGF } \beta \text { receptor signalling } \\
\text { pathway }\end{array}$ & $1.20 \mathrm{E}-11$ & $\begin{array}{l}\text { TGF } \beta \text { receptor signalling } \\
\text { pathway }\end{array}$ & $1.28 \mathrm{E}-17$ \\
\hline $\begin{array}{l}\text { TGFß receptor signalling } \\
\text { pathway }\end{array}$ & $1.60 \mathrm{E}-15$ & $\begin{array}{l}\text { Regulation of systemic arterial blood } \\
\text { pressure by renin angiotensin }\end{array}$ & 8.97E-10 & $\begin{array}{l}\text { Establishment of planar } \\
\text { polarity of embryonic } \\
\text { epithelium }\end{array}$ & $3.45 \mathrm{E}-11$ & $\begin{array}{l}\text { Positive regulation of leukocyte } \\
\text { chemotaxis }\end{array}$ & $4.68 \mathrm{E}-17$ \\
\hline $\begin{array}{l}\text { Transmembrane receptor } \\
\text { protein serine/threonine kinase } \\
\text { signalling pathway }\end{array}$ & $9.40 \mathrm{E}-14$ & $\begin{array}{l}\text { Chemokine-mediated signalling } \\
\text { pathway }\end{array}$ & $1.02 \mathrm{E}-08$ & Protein trimerisation & $4.22 \mathrm{E}-11$ & $\begin{array}{l}\text { Positive regulation of } \\
\text { chemotaxis }\end{array}$ & $1.18 \mathrm{E}-16$ \\
\hline Striated muscle cell proliferation & $3.68 \mathrm{E}-13$ & Regulation of blood pressure & $1.76 \mathrm{E}-08$ & $\begin{array}{l}\text { Response to prostaglandin } \\
\text { E stimulus }\end{array}$ & $7.79 \mathrm{E}-11$ & $\begin{array}{l}\text { Regulation of protein } \\
\text { processing }\end{array}$ & $1.29 \mathrm{E}-16$ \\
\hline Bone morphogenesis & $9.59 \mathrm{E}-13$ & Response to amine stimulus & $1.81 \mathrm{E}-08$ & Lung alveolus development & $1.60 \mathrm{E}-10$ & $\begin{array}{l}\text { Extracellular structure } \\
\text { organisation }\end{array}$ & $2.17 \mathrm{E}-16$ \\
\hline Bone development & $1.06 \mathrm{E}-12$ & Regulation of cell migration & $2.66 \mathrm{E}-08$ & $\begin{array}{l}\text { Transmembrane receptor } \\
\text { protein serine/threonine } \\
\text { kinase signalling pathway }\end{array}$ & $1.81 \mathrm{E}-10$ & $\begin{array}{l}\text { Extracellular matrix } \\
\text { organisation }\end{array}$ & $2.17 \mathrm{E}-16$ \\
\hline Cardiac muscle cell proliferation & $2.04 \mathrm{E}-12$ & Renal system process & $4.33 \mathrm{E}-08$ & $\begin{array}{l}\text { Collagen fibril } \\
\text { organisation }\end{array}$ & $2.45 \mathrm{E}-10$ & $\begin{array}{l}\text { Regulation of leukocyte } \\
\text { migration }\end{array}$ & $2.80 \mathrm{E}-16$ \\
\hline Cardiac muscle tissue growth & $4.78 \mathrm{E}-12$ & Response to acid & $5.40 \mathrm{E}-08$ & $\begin{array}{l}\text { Respiratory tube } \\
\text { development }\end{array}$ & $3.61 \mathrm{E}-10$ & $\begin{array}{l}\text { Negative regulation of TGF } \beta \\
\text { receptor signalling pathway }\end{array}$ & $1.29 \mathrm{E}-15$ \\
\hline Cardiac muscle cell apoptosis & $4.88 \mathrm{E}-12$ & $\begin{array}{l}\text { Regulation of blood volume by renin } \\
\text { angiotensin }\end{array}$ & $1.36 \mathrm{E}-07$ & $\begin{array}{l}\text { Regulation of establishment } \\
\text { of planar polarity }\end{array}$ & $3.74 \mathrm{E}-10$ & Mononuclear cell migration & $4.75 \mathrm{E}-15$ \\
\hline Artery morphogenesis & $1.73 \mathrm{E}-11$ & Regulation of cell motility & $1.57 \mathrm{E}-07$ & $\begin{array}{l}\text { Wnt receptor signalling } \\
\text { pathway. Planar cell } \\
\text { polarity pathway }\end{array}$ & $3.74 \mathrm{E}-10$ & $\begin{array}{l}\text { Negative regulation of } \\
\text { transmembrane receptor protein } \\
\text { serine/threonine kinase } \\
\text { signalling pathway }\end{array}$ & $5.67 \mathrm{E}-15$ \\
\hline $\begin{array}{l}\text { Negative regulation of } \\
\text { transmembrane receptor protein } \\
\text { serine/threonine kinase } \\
\text { signalling pathway }\end{array}$ & $2.58 \mathrm{E}-11$ & Positive regulation of angiogenesis & $2.13 \mathrm{E}-07$ & $\begin{array}{l}\text { Negative regulation of } \\
\text { epithelial cell proliferation }\end{array}$ & $5.48 \mathrm{E}-10$ & Vasculature development & $1.65 \mathrm{E}-14$ \\
\hline Artery development & $5.77 \mathrm{E}-11$ & Collagen fibril organisation & 3.97E-07 & $\begin{array}{l}\text { Cellular response to amino } \\
\text { acid stimulus }\end{array}$ & $5.54 \mathrm{E}-10$ & Angiogenesis & $1.68 \mathrm{E}-14$ \\
\hline $\begin{array}{l}\text { Negative regulation of epithelial } \\
\text { to mesenchymal transition }\end{array}$ & $6.24 \mathrm{E}-11$ & Regulation of locomotion & $4.42 \mathrm{E}-07$ & Lung development & $7.23 \mathrm{E}-10$ & Positive regulation of behaviour & $3.02 \mathrm{E}-14$ \\
\hline Muscle cell apoptosis & $1.02 \mathrm{E}-10$ & $\begin{array}{l}\text { Regulation of cellular component } \\
\text { movement }\end{array}$ & $4.75 \mathrm{E}-07$ & $\begin{array}{l}\text { Positive regulation of } \\
\text { smoothened signalling } \\
\text { pathway }\end{array}$ & $1.06 \mathrm{E}-09$ & Regulation of cell migration & $4.55 \mathrm{E}-14$ \\
\hline $\begin{array}{l}\text { Cartilage development involved } \\
\text { in endochondral bone } \\
\text { morphogenesis }\end{array}$ & $1.38 \mathrm{E}-10$ & $\begin{array}{l}\text { Negative regulation of } \\
\text { transmembrane receptor protein } \\
\text { serine/threonine kinase signalling } \\
\text { pathway }\end{array}$ & $5.76 \mathrm{E}-07$ & $\begin{array}{l}\text { Establishment of planar } \\
\text { polarity involved in neural } \\
\text { tube closure }\end{array}$ & $2.35 \mathrm{E}-09$ & $\begin{array}{l}\text { Positive regulation of cell } \\
\text { migration }\end{array}$ & $5.35 \mathrm{E}-14$ \\
\hline Cell-substrate adhesion & $1.46 \mathrm{E}-10$ & $\begin{array}{l}\text { Cellular response to organic } \\
\text { nitrogen }\end{array}$ & $5.87 \mathrm{E}-07$ & $\begin{array}{l}\text { Cellular response to amine } \\
\text { stimulus }\end{array}$ & $3.16 \mathrm{E}-09$ & Blood vessel morphogenesis & $5.62 \mathrm{E}-14$ \\
\hline $\begin{array}{l}\text { Negative regulation of cell } \\
\text { morphogenesis involved in } \\
\text { differentiation }\end{array}$ & $2.02 \mathrm{E}-10$ & Response to organic nitrogen & $6.55 \mathrm{E}-07$ & $\begin{array}{l}\text { Positive regulation of } \\
\text { filopodium assembly }\end{array}$ & $3.29 \mathrm{E}-09$ & Blood vessel development & $6.98 \mathrm{E}-14$ \\
\hline
\end{tabular}

Overlap in gene function in biological pathways is indicated in bold.

ELN, elastin; FBLN5, fibulin-5; LTBP2, latent transforming growth factor $\beta$ binding protein 2; MFAP4, microfibrillar associated protein 4; MGI, mouse genome informatics;

TGF $\beta$, transforming growth factor $\beta$.

figure S2A). Moreover, strong coexpression was observed between these four elastogenesis genes (see online supplemental figure S2B), which shows the robustness of our findings and validates the similarity in the predicted function for these four genes.

\section{FBLN5 is expressed in primary pulmonary fibroblasts} and strongly induced by TGF $\beta$

As pulmonary fibroblasts are the main source of ECM proteins in the lung, and thus important for elastic fibre formation, we investigated FBLN5 gene expression levels in primary pulmonary fibroblasts derived from patients with COPD and non-COPD controls from the Groningen cohort. To this end, fibroblasts were treated with or without TGF $\beta$ and CSE (figure 4). Under basal conditions there was no significant difference in FBLN5 expression between COPD and non-COPD control fibroblasts, although COPD fibroblasts tended to have higher expression. However, there was a clear increase in FBLN5 expression after TGF $\beta$ treatment in pulmonary 
Table 3B Gene function prediction in mouse knockout phenotypes

\begin{tabular}{|c|c|c|c|c|c|c|c|}
\hline \multicolumn{2}{|l|}{ ELN } & \multicolumn{2}{|l|}{ FBLN5 } & \multicolumn{2}{|l|}{ MFAP4 } & \multicolumn{2}{|l|}{ LTBP2 } \\
\hline MGI & $\mathrm{p}$ Value & MGI & $\mathrm{p}$ Value & MGI & p Value & MGI & $\mathrm{p}$ Value \\
\hline Abnormal tendon morphology & $5.65 \mathrm{E}-18$ & $\begin{array}{l}\text { Abnormal aorta elastic tissue } \\
\text { morphology }\end{array}$ & 4.09E-19 & $\begin{array}{l}\text { Overexpanded pulmonary } \\
\text { alveoli }\end{array}$ & $8.32 \mathrm{E}-38$ & Osteoarthritis & $1.01 \mathrm{E}-29$ \\
\hline $\begin{array}{l}\text { Centrally nucleated skeletal } \\
\text { muscle fibres }\end{array}$ & $2.99 \mathrm{E}-15$ & $\begin{array}{l}\text { Abnormal aorta wall } \\
\text { morphology }\end{array}$ & $2.73 E-18$ & $\begin{array}{l}\text { Abnormal aorta elastic tissue } \\
\text { morphology }\end{array}$ & $1.70 \mathrm{E}-36$ & Emphysema & 1.43E-24 \\
\hline $\begin{array}{l}\text { Abnormal cutaneous collagen } \\
\text { fibril morphology }\end{array}$ & $3.94 \mathrm{E}-15$ & $\begin{array}{l}\text { Abnormal cutaneous collagen } \\
\text { fibril morphology }\end{array}$ & 5.07E-17 & Abnormal aorta wall morphology & $4.75 \mathrm{E}-31$ & $\begin{array}{l}\text { Abnormal aorta elastic tissue } \\
\text { morphology }\end{array}$ & $1.43 \mathrm{E}-19$ \\
\hline Myopathy & $1.22 \mathrm{E}-13$ & Abnormal tendon morphology & $7.93 \mathrm{E}-16$ & Loose skin & $2.52 \mathrm{E}-29$ & $\begin{array}{l}\text { Abnormal pulmonary elastic } \\
\text { fibre morphology }\end{array}$ & 2.10E-18 \\
\hline $\begin{array}{l}\text { Abnormal tracheal cartilage } \\
\text { morphology }\end{array}$ & $1.98 \mathrm{E}-13$ & Loose skin & $1.52 \mathrm{E}-12$ & Emphysema & $2.18 \mathrm{E}-27$ & Abnormal tendon morphology & 4.66E-16 \\
\hline $\begin{array}{l}\text { Abnormal lung vasculature } \\
\text { morphology }\end{array}$ & $1.20 \mathrm{E}-12$ & $\begin{array}{l}\text { Abnormal pulmonary artery } \\
\text { morphology }\end{array}$ & $2.81 \mathrm{E}-10$ & Corneal thinning & $8.77 \mathrm{E}-23$ & $\begin{array}{l}\text { Dilated respiratory } \\
\text { conducting tubes }\end{array}$ & 2.27E-14 \\
\hline Loose skin & $1.23 \mathrm{E}-11$ & Emphysema & $3.21 \mathrm{E}-10$ & Abnormal tendon morphology & $9.54 \mathrm{E}-23$ & $\begin{array}{l}\text { Abnormal aorta wall } \\
\text { morphology }\end{array}$ & $6.85 E-14$ \\
\hline Osteoarthritis & $4.73 \mathrm{E}-11$ & Dystrophic muscle & $1.00 \mathrm{E}-08$ & $\begin{array}{l}\text { Abnormal cutaneous collagen fibril } \\
\text { morphology }\end{array}$ & $1.31 \mathrm{E}-22$ & $\begin{array}{l}\text { Abnormal cutaneous collagen } \\
\text { fibril morphology }\end{array}$ & $1.10 \mathrm{E}-13$ \\
\hline Emphysema & $8.53 \mathrm{E}-11$ & $\begin{array}{l}\text { Overexpanded pulmonary } \\
\text { alveoli }\end{array}$ & $4.22 \mathrm{E}-08$ & Abnormal blood vessel physiology & $3.84 \mathrm{E}-16$ & $\begin{array}{l}\text { Overexpanded pulmonary } \\
\text { alveoli }\end{array}$ & $2.20 \mathrm{E}-13$ \\
\hline $\begin{array}{l}\text { Dilated respiratory } \\
\text { conducting tubes }\end{array}$ & $1.39 \mathrm{E}-10$ & $\begin{array}{l}\text { Increased systemic arterial } \\
\text { systolic blood pressure }\end{array}$ & 7.93E-08 & $\begin{array}{l}\text { Dilated respiratory conducting } \\
\text { tubes }\end{array}$ & $1.70 \mathrm{E}-15$ & $\begin{array}{l}\text { Abnormal tracheal cartilage } \\
\text { morphology }\end{array}$ & 3.99E-12 \\
\hline Dystrophic muscle & 4.73E-10 & Dilated heart atrium & $1.91 \mathrm{E}-07$ & $\begin{array}{l}\text { Abnormal lung vasculature } \\
\text { morphology }\end{array}$ & 3.13E-15 & Abnormal lung morphology & $2.58 \mathrm{E}-11$ \\
\hline $\begin{array}{l}\text { Overexpanded pulmonary } \\
\text { alveoli }\end{array}$ & $1.14 \mathrm{E}-09$ & $\begin{array}{l}\text { Abnormal vascular smooth } \\
\text { muscle physiology }\end{array}$ & $3.56 \mathrm{E}-07$ & $\begin{array}{l}\text { Impaired lung alveolus } \\
\text { development }\end{array}$ & $1.83 \mathrm{E}-14$ & Impaired wound healing & $5.90 \mathrm{E}-11$ \\
\hline $\begin{array}{l}\text { Increased variability of } \\
\text { skeletal muscle fibre size }\end{array}$ & $1.29 \mathrm{E}-09$ & Decreased skin tensile strength & $4.88 \mathrm{E}-07$ & $\begin{array}{l}\text { Abnormal kidney medulla } \\
\text { morphology }\end{array}$ & $2.20 \mathrm{E}-14$ & Loose skin & $2.01 \mathrm{E}-10$ \\
\hline Muscle degeneration & $1.34 \mathrm{E}-09$ & Abnormal artery morphology & $5.82 \mathrm{E}-07$ & $\begin{array}{l}\text { Abnormal pulmonary elastic } \\
\text { fibre morphology }\end{array}$ & $5.33 \mathrm{E}-14$ & Brain inflammation & 2.20E-10 \\
\hline $\begin{array}{l}\text { Abnormal vertebral body } \\
\text { morphology }\end{array}$ & $1.34 \mathrm{E}-09$ & $\begin{array}{l}\text { Dilated respiratory } \\
\text { conducting tubes }\end{array}$ & $1.07 \mathrm{E}-06$ & $\begin{array}{l}\text { Increased systemic arterial systolic } \\
\text { blood pressure }\end{array}$ & $9.43 \mathrm{E}-14$ & Abnormal joint morphology & $4.30 \mathrm{E}-10$ \\
\hline Small thoracic cavity & $1.48 \mathrm{E}-09$ & Skeletal muscle fibre necrosis & $1.74 \mathrm{E}-06$ & $\begin{array}{l}\text { Increased type II pneumocyte } \\
\text { number }\end{array}$ & $1.03 \mathrm{E}-12$ & $\begin{array}{l}\text { Decreased susceptibility to } \\
\text { injury }\end{array}$ & $6.72 \mathrm{E}-10$ \\
\hline Kidney cortex atrophy & 4.83E-09 & Partial perinatal lethality & $2.99 \mathrm{E}-06$ & Small lung & $4.12 \mathrm{E}-12$ & $\begin{array}{l}\text { Abnormal pulmonary alveolus } \\
\text { morphology }\end{array}$ & $1.50 \mathrm{E}-09$ \\
\hline Pulmonary hypoplasia & $6.17 \mathrm{E}-09$ & $\begin{array}{l}\text { Abnormal lung vasculature } \\
\text { morphology }\end{array}$ & $3.12 \mathrm{E}-06$ & $\begin{array}{l}\text { Impaired branching involved in } \\
\text { ureteric bud morphogenesis }\end{array}$ & $8.23 \mathrm{E}-12$ & $\begin{array}{l}\text { Abnormal involution of the } \\
\text { mammary gland }\end{array}$ & $2.80 \mathrm{E}-09$ \\
\hline $\begin{array}{l}\text { Abnormal aorta wall } \\
\text { morphology }\end{array}$ & $9.20 \mathrm{E}-09$ & Polyuria & 4.06E-06 & Abnormal lung saccule morphology & $1.71 \mathrm{E}-11$ & Abnormal thoracic cage shape & $3.56 \mathrm{E}-09$ \\
\hline Respiratory distress & $9.23 \mathrm{E}-09$ & Renal tubule atrophy & $6.16 \mathrm{E}-06$ & Abnormal artery morphology & $2.40 \mathrm{E}-11$ & $\begin{array}{l}\text { Abnormal heart ventricle } \\
\text { morphology }\end{array}$ & 4.21E-09 \\
\hline
\end{tabular}

Overlap in mouse knockout phenotypes is indicated in bold.

$E L N$, elastin; FBLN5, fibulin-5; LTBP2, latent transforming growth factor $\beta$ binding protein $2 ; M F A P 4$, microfibrillar associated protein 4; MGl, mouse genome informatics;

TGF $\beta$, transforming growth factor $\beta$.

fibroblasts, indicating a repair response. CSE exposure did not affect FBLN5 expression in pulmonary fibroblasts.

\section{FBLN5, MFAP4 and LTBP2 are localised in elastic fibres in the lung}

Immunohistochemistry was performed on serial cut lung tissue sections to assess colocalisation of FBLN5, MFAP4 and LTBP2 with elastic fibres in the lung. Figure 5 shows clear staining of FBLN5 in alveolar and vessel walls, and surrounding the airways, which was similar in localisation to elastin. LTBP2 and MFAP4 staining was present in vessel walls and the matrix surrounding airways and vessels. LTBP2 and MFAP4 were also present in areas containing elastic fibres.

\section{Increased FBLN5 protein levels in COPD lung tissue}

FBLN5, ELN and MFAP4 protein levels were analysed in lung tissue samples from 24 patients with COPD and 19 non-COPD controls from the Groningen cohort (see online supplementary table S3) by western blot.

Total levels of FBLN5 protein were significantly higher in COPD than control lung tissue (figure 6A), an effect most clearly seen when comparing control ex-smokers and COPD stage IV ex-smokers. We also demonstrated the presence of cleaved FBLN5 protein in lung tissue and found higher levels in COPD compared with control lung tissue (figure 6B).

There were no significant differences in total protein levels of ELN and MFAP4 between COPD and control lung tissue (see online supplemental figure S3), yet ELN protein levels were lower in current than ex-smoking controls.

\section{DISCUSSION}

Using genome-wide gene expression analyses on a large dataset of lung tissue specimens from patients with COPD and non-COPD controls, we identified a clear gene signature for 


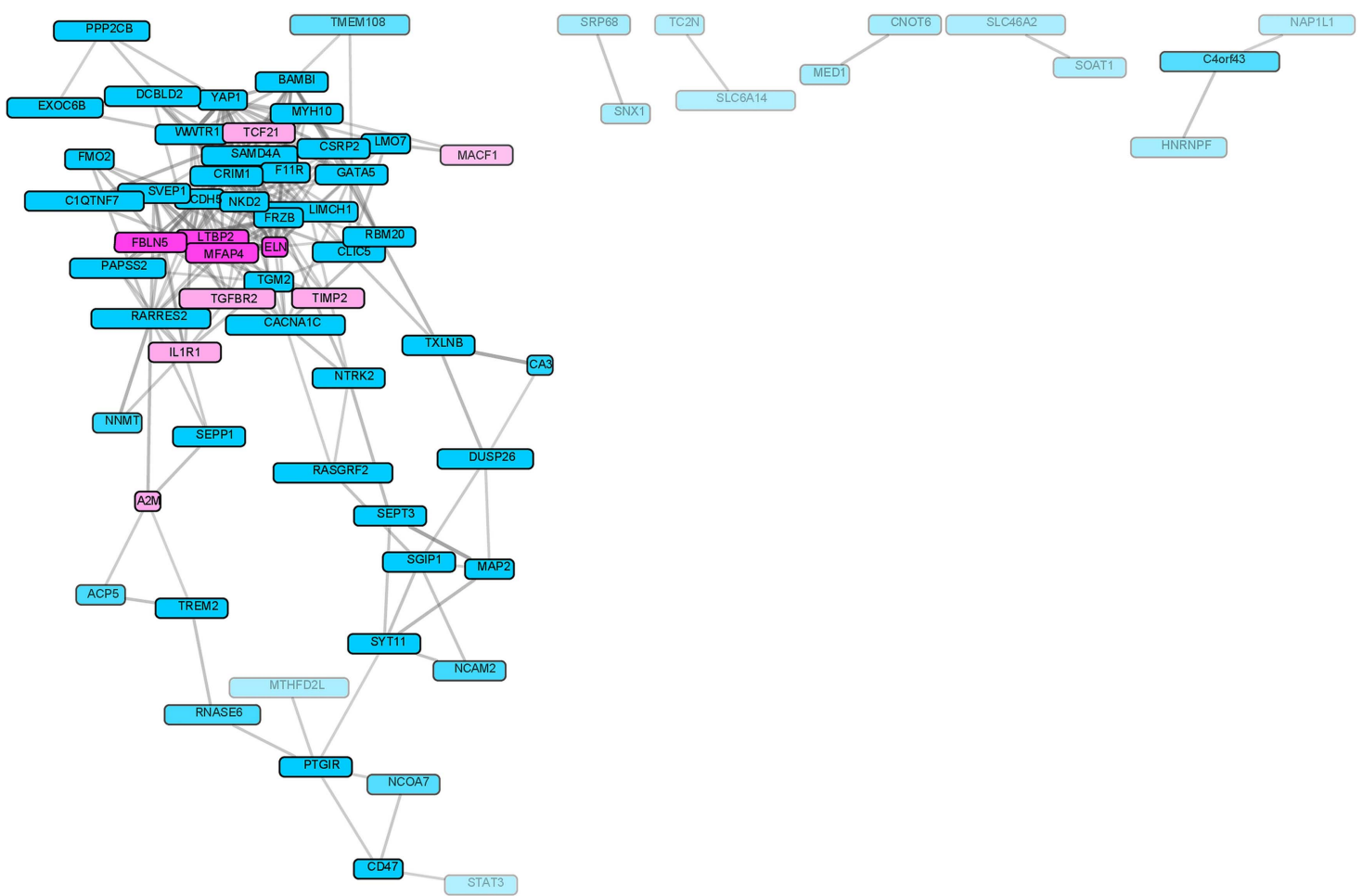

Figure 2 Cofunctionality network of genes upregulated in patients with chronic obstructive pulmonary disease (COPD). The cofunctionality network shows the clustering of all genes that are upregulated in COPD lung tissue at $p<0.001$. The clustering is based on the overlap in gene function as predicted by our GeneNetwork; that is, close clustering means high overlap in predicted gene function. The four elastogenesis genes are highlighted in dark pink and cluster together in the centre of the network. Several other genes relevant for COPD pathogenesis are highlighted in light pink.

elastogenesis in COPD, with increased expression of ELN, FBLN5, MFAP4 and LTBP2. Among the upregulated genes in COPD, we demonstrated a clear enrichment of genes that are known to induce an emphysematous phenotype if knocked out in mice, including FBLN5. Additionally, we validated part of our gene expression findings using qPCR and showed a negative correlation between FBLN5, ELN and MFAP4 expression and lung function. We showed strong correlations between the gene expression of ELN, FBLN5, MFAP4 and LTBP2 and we observed colocalisation of FBLN5, MFAP4 and LTBP2 protein with elastic fibres in lung tissue. Thus the presence of these elastogenesis genes and proteins is strongly related in lung tissue, in line with the overlap in gene function that we predicted using our independent gene expression dataset. Finally, we demonstrated higher protein levels of total FBLN5 and cleaved FBLN5 protein in lung tissue from patients with COPD than non-COPD controls.

The gene that was most significantly upregulated in COPD, and most interesting with respect to COPD pathogenesis, was FBLN5. FBLN5 is essential for elastic fibre assembly and abundantly expressed during lung and vascular development. ${ }^{14}$ FBLN5 knockout mice survive to adulthood but develop pronounced elastinopathy with human aging phenotypes like loose skin, vascular abnormalities, severe emphysema and genital prolapse. ${ }^{15} 16$ This phenotype in mice is very similar to the human connective tissue disorder cutis laxa, which can be caused by mutations in FBLN5 and is often associated with severe emphysema. ${ }^{19}$ Based on these findings we consider FBLN5 as a potential novel player in tissue repair in COPD and decided to further focus on this gene. Next to FBLN5 and ELN itself, two other genes related to elastogenesis, that is, MFAP4 and LTBP2, were also upregulated in COPD. MFAP4 colocalises with elastin in the lung ${ }^{18}$ and LTBP2 has been shown to interact with FBLN5 and promote elastic fibre assembly. ${ }^{17}$

Interestingly, FBLN5, LTBP2 and MFAP4 were present in elastic fibres in all lung compartments, hence they could potentially be involved in vascular and matrix related changes associated with emphysema and COPD, which may be relevant for further studies.

Our findings are intriguing yet paradoxical as elastic fibres are destroyed with emphysema, resulting in severely impaired lung elasticity in COPD. We propose that upregulation of these elastogenesis genes in COPD is the result of an attempt to repair the damaged lung, an attempt that is not effective. This hypothesis is supported by the observation that FBLN5 gene expression increases after elastase-induced emphysema in mice, ${ }^{20}$ and is also in line with previous studies demonstrating increased elastin gene expression in severe COPD. ${ }^{21}$ Furthermore, our results and those of Kuang et $a l,{ }^{22}$ showing increased FBLN5 gene expression after TGF $\beta$ treatment in lung fibroblasts, support a role for FBLN5 in repair responses.

A possible explanation for the fact that this repair response in COPD is not effective might be found in defects in protein translation. Two studies have now demonstrated that the FBLN5 protein can be cleaved by serine proteases ${ }^{23} 24$ and increased levels of this cleaved form of FBLN5 protein were demonstrated in the skin of aged mice. ${ }^{23}$ This is intriguing as on the one hand COPD has been regarded as an aging lung disease $e^{25} 26$ and on the other hand increased serine protease activity is present in COPD lungs, which is thought to play an important role in emphysematous lung tissue destruction. ${ }^{27}{ }^{28}$ Moreover, the cleaved form of FBLN5 does not promote elastic fibre assembly in vitro, and thus seems to be non-functional. ${ }^{23}$ To investigate the role of cleaved FBLN5, we measured its protein expression 
Figure 3 Quantitative PCR validation. (A) Fibulin-5 (FBLN5), elastin (ELN), microfibrillar associated protein 4 (MFAP4) and latent transforming growth factor $\beta$ binding protein 2 (LTBP2) mRNA expression relative to housekeeping gene expression in lung tissue comparing patients with chronic obstructive pulmonary disease (COPD) (closed symbols) and non-COPD controls (open symbols). The results of the MannWhitney $U$ (MWU) analyses are depicted in the figure. (B) The negative correlation between the expression of FBLN5 in lung tissue and $\mathrm{FEV}_{1} \%$ predicted is shown. The result of the Spearman correlation is depicted below the figure.
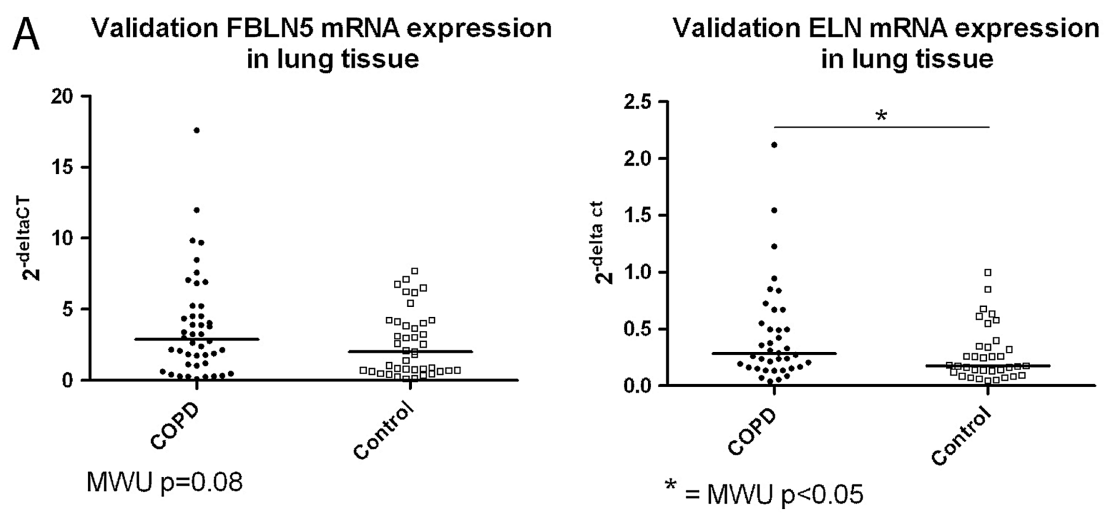

Validation MFAP4 mRNA expression in lung tissue
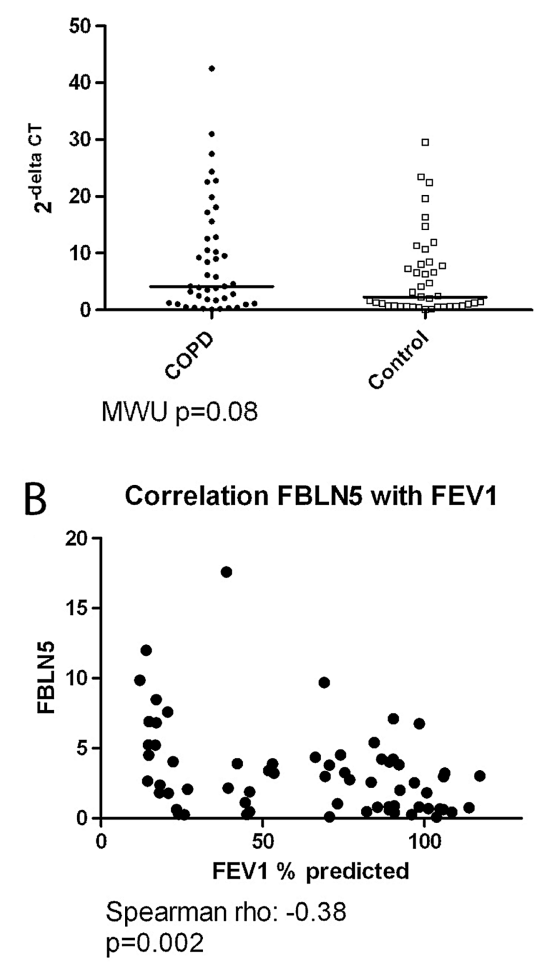

in lung tissue and found higher levels in patients with COPD than in non-COPD controls.

In addition to the four genes related to elastogenesis, we found several other genes to be upregulated in COPD lung tissue that might be relevant for COPD pathogenesis. MACF1 is involved in the actin cytoskeleton organisation and was demonstrated to be a positive regulator of WNT signalling, ${ }^{29}$ an important lung developmental pathway. ${ }^{30}$ TGFBR2 is one of the receptors for TGF $\beta$, which is involved in many cellular processes including lung development and wound repair and often implicated in COPD. ${ }^{31}$ TCF21 is involved in epithelialmesenchymal interactions in kidney and lung morphogenesis and is important in epithelial differentiation and branching morphogenesis. $^{32} \alpha 2$-Macroglobulin (A2M) is a protease inhibitor and a genetic defect in this gene has been associated with COPD. ${ }^{33}$

Among the downregulated genes in COPD lung tissue, VEGFA and POSTN were most relevant for COPD pathogenesis. VEGF is an important stimulator of angiogenesis and decreased VEGF levels have been associated with emphysema in humans and in mice. ${ }^{34}$ POSTN is a matricellular protein that has been associated with $\mathrm{T}$ helper 2 related subepithelial fibrosis in asthma $^{35}$ and progression of fibrosis in patients with idiopathic pulmonary fibrosis. ${ }^{36}$

A strength of our study was the very stringent way of analysing gene expression data. To identify the differentially expressed genes we corrected for age, gender, smoking status and packyears and studied each of the three cohorts separately and subsequently conducted a meta-analysis. However, we also corrected the expression data for the 25 most dominant expression effects (identified by principal component analysis). One reason to do this is that some of these components might capture unknown, confounding factors that otherwise could result in false positive associations. While this approach invariably will result in false negative findings, the small set of genes that we report on here showed a highly consistent expression difference between cases and controls that was present in each of the three cohorts, showing the robustness of our findings. Opposed to our stringent approach we decided to use a lenient FDR cut-off of $20 \%$ to assess the differentially expressed genes. This resulted in 252 


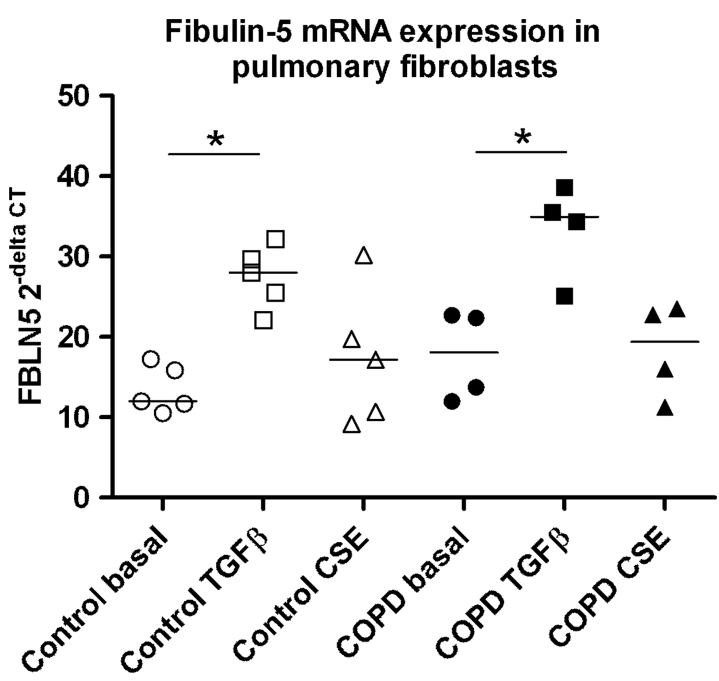

Figure 4 Fibulin-5 (FBLN5) expression in pulmonary fibroblasts. FBLN5 gene expression in pulmonary fibroblasts from control subjects (open symbols. $n=5$ ) and patients with chronic obstructive pulmonary disease (COPD) (closed symbols, $n=4$ ) is shown during basal conditions (circles) and after transforming growth factor $\beta$ (TGF $\beta$ ) (squares) and cigarette smoke extract (CSE) (triangles) treatment. Differences between the groups were tested by Mann-Whitney U tests. ${ }^{*} p<0.05$.

differentially expressed genes as opposed to 51.6 that are expected by chance. The FDR was estimated very conservatively, assuming that the 52738 tests (ie, each probe present on the expression platform) were entirely uncorrelated. In reality, this is not the case, since many probes (especially those mapping within the same gene) typically show strong coexpression. As such we feel confident that the actual FDR of these 252 differentially expressed probes is lower than 20\%. We choose this FDR as a hypothesis generating cut-off, and this might give some false positive results. Therefore we performed several follow-up experiments and validated our main findings on mRNA and protein level, demonstrated colocalisation with elastic fibres in lung tissue and showed cofunctionality between the upregulated genes.

We used a novel method that can accurately predict gene function based on an independent gene expression dataset of 77840 samples. A clear overlap in predicted gene function was found for the genes related to elastogenesis and for the other upregulated genes which are relevant for COPD pathogenesis. Visualisation in a cofunctionality network showed that these genes share many functions. Moreover, among the genes upregulated in COPD, enrichment was found for genes that are predicted to give an emphysematous phenotype in knockout mice, confirming that our results are indeed specific for COPD.

In conclusion, we identified a clear elastogenesis gene signature in COPD, with increased gene expression of ELN, FBLN5, MFAP4 and LTBP2 in lung tissue. We provide evidence for FBLN5 as a novel player in abnormal tissue repair in COPD. We suggest that increased FBLN 5 mRNA expression in COPD lungs is due to a response to tissue damage and repair, and that cleavage of FBLN5 protein is increased in COPD lungs due to high serine protease activity. Cleaved FBLN5 is non-functional and does not contribute to elastic fibre assembly and tissue repair in COPD. Functional studies are currently ongoing to unravel the exact role of FBLN5 in tissue repair in COPD.

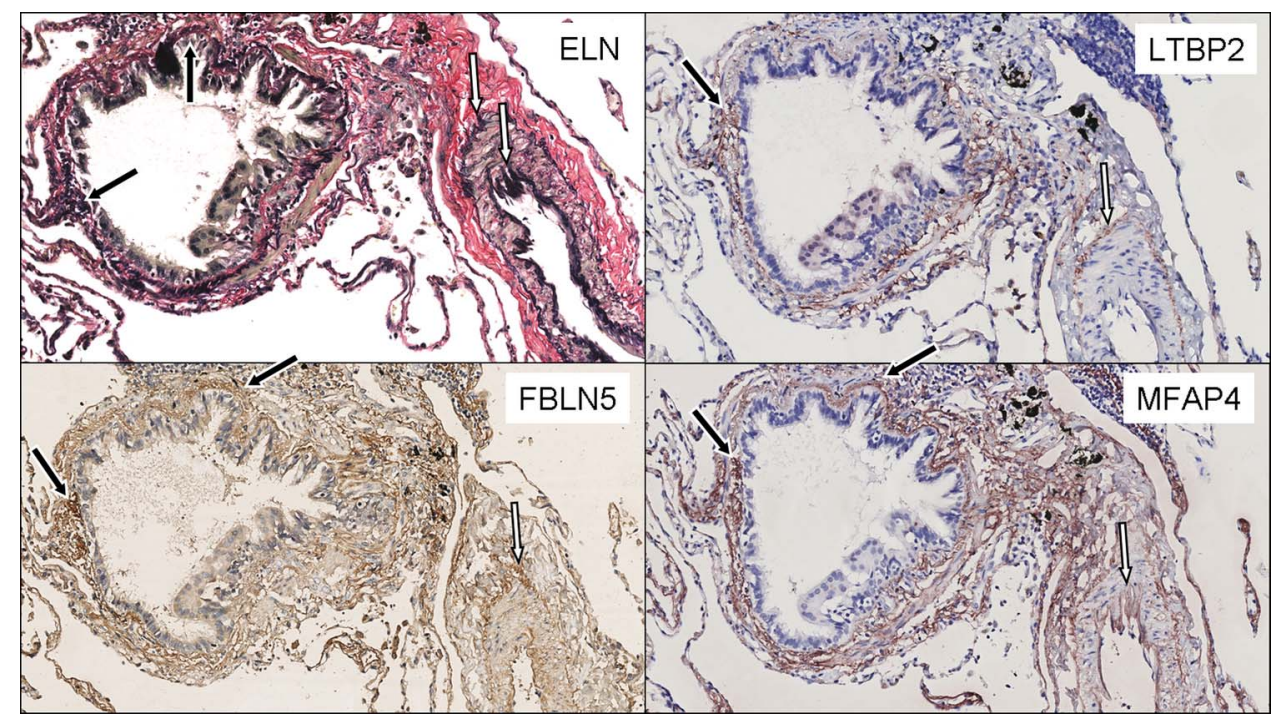

Figure 5 Elastin (ELN), fibulin-5 (FBLN5), latent transforming growth factor $\beta$ binding protein 2 (LTBP2) and microfibrillar associated protein 4 (MFAP4) staining in lung tissue. Presence of elastic fibres (black) is demonstrated with a Verhoeff van Gieson stain in the upper left panel. LTBP2 and MFAP4 staining (red) is shown in the right upper and lower panel, respectively. FBLN5 staining (brown) is shown in the lower left panel. Examples of colocalisation with elastic fibres are indicated with black arrows in the matrix around the airways and white arrows in the vessel walls. 
A Total FBLN5 protein in lung tissue
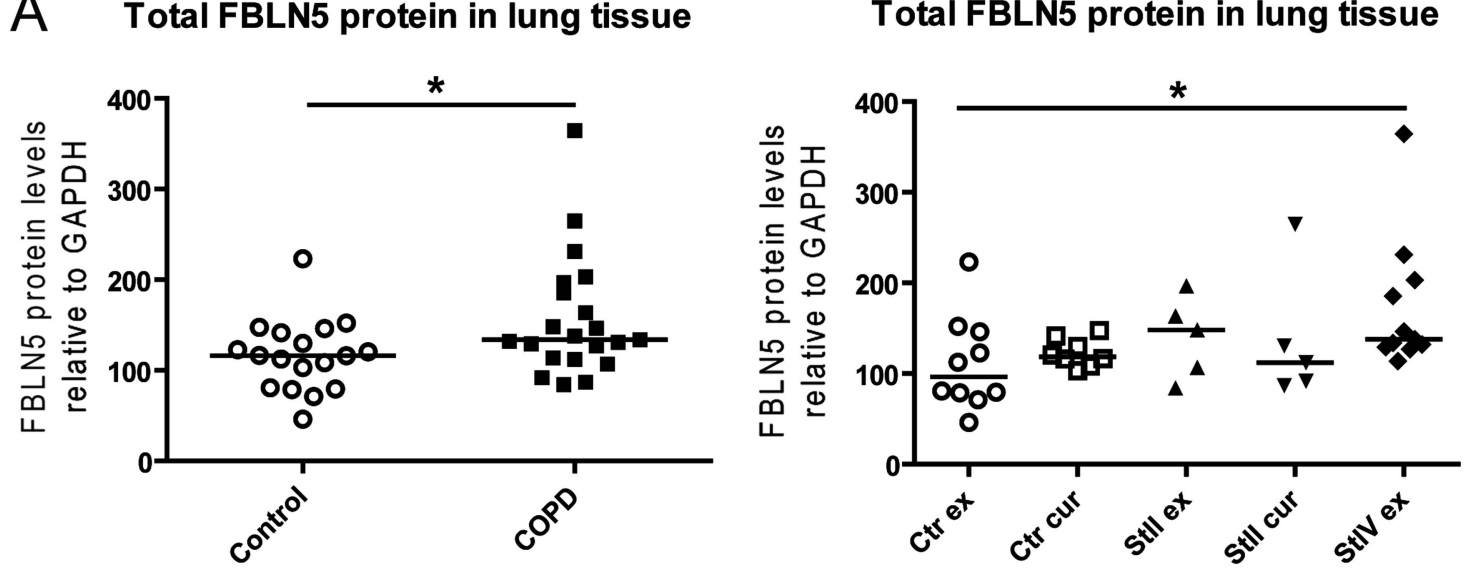

Total FBLN5 protein in lung tissue
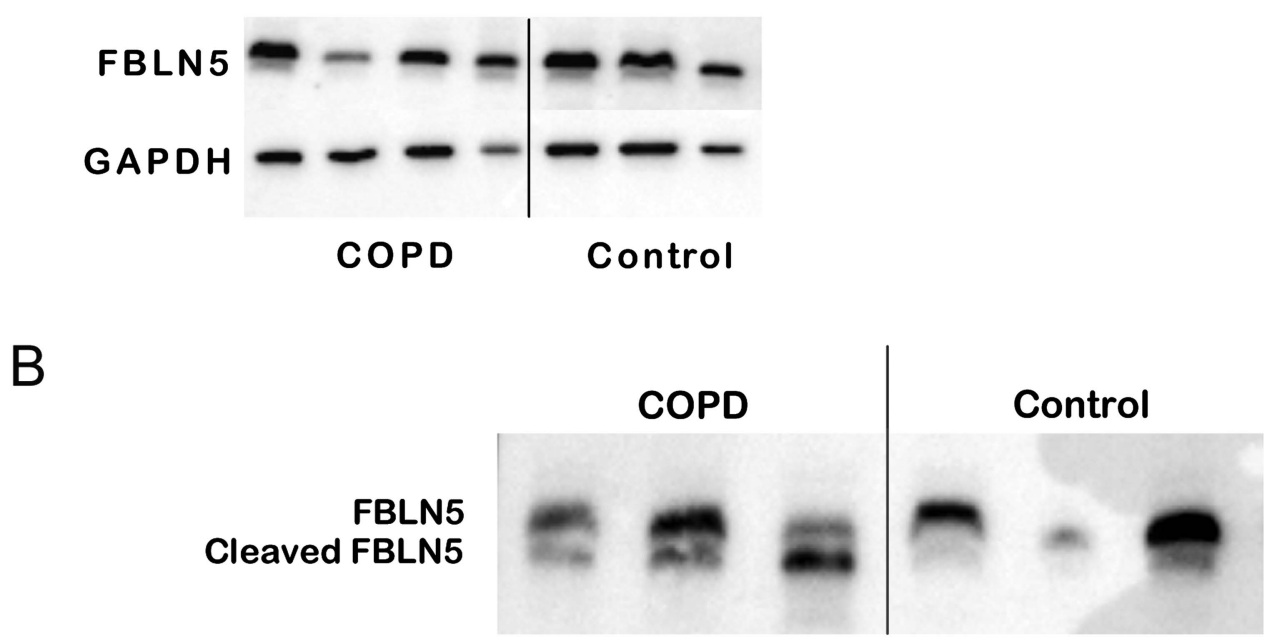

Figure 6 Total and cleaved fibulin-5 (FBLN5) protein levels in lung tissue. (A) FBLN5 protein levels relative to GAPDH expression in lung tissue comparing patients with chronic obstructive pulmonary disease (COPD) and non-COPD controls. The left graph shows the comparison between all patients with COPD (closed symbols) and controls (open symbols). The right graph shows the subgroups based on smoking status and COPD stages. A representative western blot of FBLN5 and GAPDH is shown below the graphs. Differences between the groups were tested by Mann-Whitney U tests. ${ }^{*} p<0.05$. (B) Western blot staining showing total FBLN5 and cleaved FBLN5 protein levels in lung tissue of three patients with COPD and three non-COPD controls. GADPH, glyceraldehyde 3-phosphate dehydrogenase.

\author{
Author affiliations \\ ${ }^{1}$ Department of Pathology and Medical Biology, University of Groningen, University \\ Medical Center Groningen, Groningen, The Netherlands \\ ${ }^{2}$ University of Groningen, University Medical Center Groningen, Groningen Research \\ Institute for Asthma and COPD, Groningen, The Netherlands \\ ${ }^{3}$ Department of Pulmonary Diseases, University of Groningen, University Medical \\ Center Groningen, Groningen, The Netherlands \\ ${ }^{4}$ The University of British Columbia, Center for Heart Lung Innovation, St Paul's \\ Hospital, Vancouver, Canada \\ ${ }^{5}$ Respiratory Division, University of British Columbia, Vancouver, Canada \\ ${ }^{6}$ Institut universitaire de cardiologie et de pneumologie de Québec, Québec, Canada \\ ${ }^{7}$ Department of Molecular Medicine, Laval University, Québec, Canada \\ ${ }^{8}$ Department of Genetics, University of Groningen, University Medical Center \\ Groningen, Groningen, The Netherlands \\ ${ }^{9}$ Merck Research Laboratories, Boston, Massachusetts, USA \\ ${ }^{10}$ Department of Molecular Pharmacology, University of Groningen, Groningen, \\ The Netherlands
}

Contributions $C-A B$ was involved in lung tissue collection and compiling the lung tissue database, contributed to the study concept and design, interpreted the data, supervised the basic laboratory research and drafted the manuscript. MvdB was involved in compiling the lung tissue database and gathering of clinical data, contributed to the study concept and design, was involved in data analyses and data interpretation, and writing of the manuscript. DSP, WT, PDP, DDS, YB, ML contributed to the study concept and design, were involved in lung tissue collection and compiling the lung tissue database, including clinical information, and the writing and final editing of the manuscript. In addition, DSP and WT contributed to the data interpretation. DCN and KH were involved in the study concept and design, edited the final manuscript and were responsible for the gene expression profiling. MRJ, AIRS and SB conducted the basic laboratory research and contributed to the writing and final editing of the manuscript. JK and RSNF developed the GeneNetwork under supervision of LF. LF had full access to all the data in the study and takes responsibility for the integrity of the data and accuracy of the data analyses. In addition, he contributed to the writing and final editing of the manuscript. C-AB and MvdB are co-first authors; WT and LF are co-last authors.

Funding This study was funded by the Dutch Lung Foundation (3.2.11.024) and Merck Research Laboratories.

Competing interests None.

Ethics approval Ethics committees of the Institut universitaire de cardiologie et de pneumologie de Québec (Quebec cohort) and the UBC-Providence Health Care Research Institute Ethics Board (Vancouver cohort).

Provenance and peer review Not commissioned; externally peer reviewed.

\section{REFERENCES}

1 Hogg JC, Timens W. The pathology of chronic obstructive pulmonary disease. Annu Rev Pathol 2009;4:435-59.

2 McDonough JE, Yuan $R$, Suzuki M, et al. Small-airway obstruction and emphysema in chronic obstructive pulmonary disease. N Eng/ J Med 2011;365:1567-75.

3 Spira A, Beane J, Pinto-Plata V, et al. Gene expression profiling of human lung tissue from smokers with severe emphysema. Am J Respir Cell Mol Biol 2004;31:601-10. 
4 Ning W, Li CJ, Kaminski N, et al. Comprehensive gene expression profiles reveal pathways related to the pathogenesis of chronic obstructive pulmonary disease. Proc Natl Acad Sci U S A 2004;101:14895-900.

5 Golpon HA, Coldren CD, Zamora MR, et al. Emphysema lung tissue gene expression profiling. Am J Respir Cell Mol Biol 2004;31:595-600.

6 Wang IM, Stepaniants S, Boie Y, et al. Gene expression profiling in patients with chronic obstructive pulmonary disease and lung cancer. Am J Respir Crit Care Med 2008;177:402-11.

7 Bhattacharya S, Srisuma S, Demeo DL, et al. Molecular biomarkers for quantitative and discrete COPD phenotypes. Am J Respir Cell Mol Biol 2009;40:359-67.

8 Hao K, Bosse Y, Nickle DC, et al. Lung eQTLs to help reveal the molecular underpinnings of Asthma. PLoS Genet 2012;8:e1003029.

9 Bosse $Y$, Sin D, Laviolette $M$, et al. Hypothesis-driven research on genomic data derived from a large scale lung EQTL mapping study. Webmed Cent Lund 2010;1: WMC00724.

10 Bosse $Y$, Postma DS, Sin DD, et al. Molecular signature of smoking in human lung tissues. Cancer Res 2012;72:3753-63.

11 Fehrmann RS, Jansen RC, Veldink JH, et al. Trans-eQTLs reveal that independent genetic variants associated with a complex phenotype converge on intermediate genes, with a major role for the HLA. PLoS Genet 2011;7:e1002197.

12 Cvejic A, Haer-Wigman L, Stephens JC, et al. SMIM1 underlies the Vel blood group and influences red blood cell traits. Nat Genet 2013;45:542-5.

13 Westra HJ, Peters MJ, Esko T, et al. Systematic identification of trans eQTLs as putative drivers of known disease associations. Nat Genet 2013;45:1238-43.

14 Yanagisawa $\mathrm{H}$, Schluterman MK, Brekken RA. Fibulin-5, an integrin-binding matricellular protein: its function in development and disease. J Cell Commun Signal 2009:3:337-47.

15 Yanagisawa H, Davis EC, Starcher BC, et al. Fibulin-5 is an elastinbinding protein essential for elastic fibre development in vivo. Nature 2002;415:168-71.

16 Nakamura T, Lozano PR, Ikeda Y, et al. Fibulin-5/DANCE is essential for elastogenesis in vivo. Nature 2002;415:171-5.

17 Hirai M, Horiguchi M, Ohbayashi T, et al. Latent TGF-beta-binding protein 2 binds to DANCE/fibulin-5 and regulates elastic fiber assembly. EMBO J 2007;26:3283-95.

18 Schlosser A, Thomsen T, Shipley JM, et al. Microfibril-associated protein 4 binds to surfactant protein A (SP-A) and colocalizes with SP-A in the extracellular matrix of the lung. Scand J Immunol 2006;64:104-16.

19 Callewaert B, Su CT, Van Damme T, et al. Comprehensive clinical and molecular analysis of 12 families with type 1 recessive cutis laxa. Hum Mutat 2013:34:111-21.
20 Kuang PP, Goldstein RH, Liu Y, et al. Coordinate expression of fibulin-5/DANCE and elastin during lung injury repair. Am J Physiol Lung Cell Mol Physiol 2003;285: L1147-52.

21 Deslee G, Woods JC, Moore CM, et al. Elastin expression in very severe human COPD. Eur Respir J 2009;34:324-31.

22 Kuang $\mathrm{PP}$, Joyce-Brady $\mathrm{M}$, Zhang $\mathrm{XH}$, et al. Fibulin-5 gene expression in human lung fibroblasts is regulated by TGF-beta and phosphatidylinositol 3-kinase activity. Am J Physiol Cell Physiol 2006:291:C1412-21.

23 Hirai M, Ohbayashi T, Horiguchi M, et al. Fibulin-5/DANCE has an elastogenic organizer activity that is abrogated by proteolytic cleavage in vivo. J Cell Biol 2007:176:1061-71.

24 Budatha M, Silva S, Montoya TI, et al. Dysregulation of protease and protease inhibitors in a mouse model of human pelvic organ prolapse. PLOS ONE 2013;8:e56376.

25 Ito K, Barnes PJ. COPD as a disease of accelerated lung aging. Chest 2009;135:173-80

26 Lee J, Sandford A, Man P, et al. Is the aging process accelarated in chronic obstructive pulmonary disease? Curr Opin Pulm Med 2011;17:90-7.

27 Hiemstra PS, van Wetering S, Stolk J. Neutrophil serine proteinases and defensins in chronic obstructive pulmonary disease: effects on pulmonary epithelium. Eur Respir J 1998;12:1200-8

28 Barnes PJ, Shapiro SD, Pauwels RA. Chronic obstructive pulmonary disease: molecular and cellular mechanisms. Eur Respir J 2003;22:672-88.

29 Chen HJ, Lin CM, Lin CS, et al. The role of microtubule actin cross-linking factor 1 (MACF1) in the Wnt signaling pathway. Genes Dev 2006;20:1933-45.

30 Pongracz JE, Stockley RA. Wnt signalling in lung development and diseases. Respir Res 2006;7:15.

31 Konigshoff $M$, Kneidinger N, Eickelberg O. TGF-beta signaling in COPD: deciphering genetic and cellular susceptibilities for future therapeutic regimen. Swiss Med Wkly 2009;139:554-63.

32 Quaggin SE, Schwartz L, Cui S, et al. The basic-helix-loop-helix protein pod1 is critically important for kidney and lung organogenesis. Development 1999;126:5771-83.

33 Poller W, Barth J, Voss B. Detection of an alteration of the alpha 2-macroglobulin gene in a patient with chronic lung disease and serum alpha 2-macroglobulin deficiency. Hum Genet 1989;83:93-6.

34 Voelkel NF, Vandivier RW, Tuder RM. Vascular endothelial growth factor in the lung. Am J Physiol Lung Cell Mol Physiol 2006;290:L209-21.

35 Takayama G, Arima K, Kanaii T, et al. Periostin: a novel component of subepithelial fibrosis of bronchial asthma downstream of IL-4 and IL-13 signals. J Allergy Clin Immunol 2006;118:98-104.

36 Naik PK, Bozyk PD, Bentley JK, et al. Periostin promotes fibrosis and predicts progression in patients with idiopathic pulmonary fibrosis. Am J Physiol Lung Cell Mol Physiol 2012;303:L1046-56. 